\title{
Reliability of subjective pain ratings and nociceptive flexion reflex responses as measures of conditioned pain modulation
}

\author{
Carlo Jurth ${ }^{1}$, Benno Rehberg $\mathrm{MD}^{2}$, Falk von Dincklage $\mathrm{MD}^{1}$
}

C Jurth, B Rehberg, F von Dincklage. Reliability of subjective pain ratings and nociceptive flexion reflex responses as measures of conditioned pain modulation. Pain Res Manag 2014;19(2):93-96.

BACKGROUND: The endogenous modulation of pain can be assessed through conditioned pain modulation (CPM), which can be quantified using subjective pain ratings or nociceptive flexion reflexes. However, to date, the test-retest reliability has only been investigated for subjective pain ratings.

OBJECTIVE: To compare the test-retest reliability of CPM-induced changes, measured using subjective pain ratings and nociceptive flexion reflexes, to provide a reliable scoring parameter for future studies.

METHOD: A total of 40 healthy volunteers each received painful electrical stimuli to the sural nerve to elicit nociceptive flexion reflexes. Reflex sizes and subjective pain ratings were recorded before and during the immersion of the contralateral hand in hot water to induce CPM as well as innocuous water as control. Measurements were repeated in a retest 28 days later.

RESULTS: Intraclass correlation coefficients showed good test-retest reliabilities of CPM during the hot water stimulus for both scoring parameters. Subjective pain ratings also correlated between test and retest during the control stimulus.

CONCLUSIONS: Subjective pain ratings and nociceptive flexion reflexes show comparable test-retest reliabilities, but they reflect different components of CPM. While subjective pain ratings appear to incorporate cognitive influences to a larger degree, reflex responses appear to reflect spinal nociception more purely.

Key Words: Conditioned pain modulation; Diffuse noxious inhibitory controls; Nociceptive flexion reflex; Test-retest reliability

$\mathrm{T}$ he concept of modulating a painful sensation by inducing a painful conditioning stimulus is often used to investigate pain pathophysiology (1). Altered pain modulation has been shown in various pain disorders $(2,3)$ and recent research indicates that it may identify patients at risk for developing chronic pain because impaired pain modulation correlates with a greater chance of acquiring pain disorders $(4,5)$.

The experimental paradigm to investigate this concept of an endogenous modulation of pain by conditioning stimuli is termed 'conditioned pain modulation' (CPM), for which a standardized conditioning stimulus is applied to inhibit an experimental painful test stimulus (6). Via spinal-supraspinal feedback loops, painful stimuli at any part of the body inhibit nociceptive transmission distant from these stimuli (7). CPM is believed to be mediated, in part, by the descending inhibition of nociceptive transmission of wide dynamic range neurons in the dorsal horn as well as in the trigeminal nuclei, a system known as diffuse noxious inhibitory controls $(8,9)$. Furthermore, modulation on the cerebral level via cortico-cortical interactions has been shown during CPM (10).

Several modalities, such as cold, ischemic, chemical or heat pain, have been used as the conditioning stimulus to inhibit the test
La fiabilité des évaluations subjectives de la douleur et des réflexes nociceptifs de flexion pour mesurer la modulation conditionnée de la douleur

HISTORIQUE : Il est possible d'évaluer la modulation endogène de la douleur par la modulation conditionnée de la douleur (MCD), qui peut être quantifiée au moyen d'évaluations subjectives de la douleur ou de réflexes nociceptifs de flexion. Cependant, jusqu'à présent, la fiabilité test-retest n'a été examinée que dans le cadre d'évaluations subjectives de la douleur.

OBJECTIF : Comparer la fiabilité test-retest des modifications induites par la MCD, mesurée par des évaluations subjectives de la douleur et des réflexes nociceptifs de flexion, afin de fournir un paramètre de pointage fiable lors de prochaines études.

MÉTHODOLOGIE : Au total, 40 volontaires en santé ont chacun reçu des stimuli électriques douloureux dans le nerf saphène externe afin de provoquer des réflexes nociceptifs de flexion. Les chercheurs ont consigné l'amplitude des réflexes et les évaluations subjectives de la douleur avant et pendant l'immersion de la main controlatérale dans de l'eau chaude afin d'induire une $\mathrm{MCD}$, ainsi que dans de l'eau tempérée comme mesure témoin. Les mesures ont été reprises 28 jours plus tard lors d'un deuxième test.

RÉSULTATS : Dans les deux paramètres de pointage, les coefficients de corrélation intraclasse ont révélé de bonnes fiabilités test-retest de la MCD pendant le stimulus dans l'eau chaude. Les évaluations subjectives de la douleur étaient également corrélées entre le test et la reprise du test pendant le stimulus témoin.

CONCLUSIONS : Les évaluations subjectives de la douleur et les réflexes nociceptifs de flexion ont une fiabilité test-retest comparable, mais ils reflètent divers aspects de la MCD. Tandis que les évaluations subjectives de la douleur semblent intégrer des influences cognitives plus vastes, les réactions de réflexe semblent refléter une nociception plus pure.

stimulus, which is commonly applied as a thermal, mechanical or electrical pain stimulus (1). To quantify the inhibitory effect of the conditioning stimulus on the test stimulus, typically each test stimulus is rated subjectively on a pain rating scale. Another method to quantify pain modulation is the nociceptive flexion reflex (NFR) $(11,12)$. The NFR is a withdrawal reflex of the leg, typically recorded using a biceps femoris muscle electromyogram following stimulation of the sural nerve at the foot. The reflex threshold and amplitude are closely related to those of the subjective pain ratings, making it an objective and reliable tool for pain assessment in CPM paradigms, which may be differentially affected by cognitive influences $(13,14)$. The NFR is known to have a good test-retest reliability (15). However, in contrast to subjective pain ratings (16-18), the reliability of the NFR to quantify the effect of CPM has not yet been investigated.

The aim of the present study was, therefore, to investigate and compare the test-retest reliability of subjective pain ratings and nociceptive reflex responses as instruments to quantify CPM in healthy volunteers to provide a reliable scoring parameter for CPM in future studies.

${ }^{1}$ Charité - Universitätsmedizin Berlin, Klinik für Anästhesiologie mit Schwerpunkt operative Intensivmedizin, Campus Charité Mitte und Campus

Virchow-Klinikum, Berlin, Germany; ${ }^{2}$ Hôpitaux Universitaires de Genève, Département d'Anesthésiologie, Pharmacologie et Soins Intensifs,

Geneva, Switzerland

Correspondence: Mr Carlo Jurth, Charité - Universitätsmedizin Berlin, Klinik für Anästhesiologie mit Schwerpunkt operative Intensivmedizin, Campus Charité Mitte, Charitéplatz 1, Berlin 10117, Germany. Telephone 49-30-450-531227, fax 49-30-450-531927, e-mail c.jurth@gmx.de 


\section{METHODS}

\section{Participants}

After approval by the ethics committee of the Charite Universitaetsmedizin Berlin (Berlin, Germany) and written informed consent, the study was conducted with 40 healthy volunteers ( 20 men and 20 women). Exclusion criteria were chronic or acute pain conditions. Each volunteer was required to abstain from analgesics for $48 \mathrm{~h}$, any drugs, caffeine and alcohol for $24 \mathrm{~h}$ as well as strenuous exercise for $6 \mathrm{~h}$ before measurements. Participants received $€ 50$ as compensation for the participation.

\section{Experimental procedure}

The study was performed during two sessions, 28 days apart. An interval of 28 days was chosen to reduce variability due to the menstrual cycle $(19,20)$, although endogenous inhibition of the NFR may not be altered by the menstrual phases (12). The measurements were conducted in a quiet, air-conditioned room and began in the morning to reduce variability due to circadian changes (21). To determine individual levels of anxiety, Spielberger's State/Trait Anxiety Inventory scores were evaluated (22). To control for differences in subjective pain perception, the volunteers completed the Pain Sensitivity Questionaire (23). The volunteer's expectations regarding the effect of the conditioning stimuli on the level of pain elicited by the test stimulus were grouped as "increase in pain", "no change" or "decrease in pain". All assessments were conducted before both sessions.

Before commencement of the electrophysiological measurements, the volunteers were positioned in a comfortable flexible chair, including a foot rest, with $120^{\circ}$ flexion in the hip, $160^{\circ}$ in the knee and $110^{\circ}$ in the ankle. They were instructed to keep their eyes closed throughout the measurements.

Electrocutaneous stimulation was applied using surface electrodes below the left lateral malleolus to stimulate the sural nerve at its retromalleolar pathway. Stimuli were applied repeatedly at interstimulus intervals randomized between $8 \mathrm{~s}$ and $12 \mathrm{~s}$ to minimize the likelihood of stimulus predictability (24). Each stimulus consisted of five rectangular pulses of $1 \mathrm{~ms}$ duration at $200 \mathrm{~Hz}$ using the computercontrolled DS5 constant current stimulator (Digitimer, United Kingdom).

To evaluate the NFR responses evoked by these stimuli, the biceps femoris electromyogram was recorded using surface electrodes placed over the biceps femoris muscle (25). Electromyographic activity was amplified by a factor of 10,000 , band-pass filtered between $2 \mathrm{~Hz}$ and $1 \mathrm{kHz}$ (g.Bsamp, gTech, Austria), digitized at $2 \mathrm{kHz}$ (Micro1401, Cambridge Electronic Design Ltd, United Kingdom), rectified and analyzed using Matlab (Matlab R2010b, MathWorks Inc, USA). The reflex interval mean z score in the interval between $90 \mathrm{~ms}$ and $180 \mathrm{~ms}$ after the stimulus was used to score the NFR magnitude (26).

\section{Experimental sequence}

To quantify the subjective pain intensity evoked by the stimuli, volunteers were instructed to rate each perceived stimulus on a numerical rating scale (NRS). This scale ranged from 0 to 100 and was anchored at either end by $0=$ 'no pain' and $100=$ 'strongest pain imaginable'.

Before the measurements, all volunteers were habituated to stimuli up to an intensity of NRS 70. Following a resting period, the stimulation intensity corresponding to a pain level of NRS 50 was determined using an up-down staircase method (27). A sequence of stimuli using the predetermined individual intensity evoking NRS 50 followed, which consisted of 15 stimuli to reach a steady state (28), 20 stimuli for the state 'before conditioning stimulus' and 20 stimuli for the state 'during conditioning stimulus'. Throughout the 200 s during which the 20 stimuli of the state 'during conditioning stimulus' were applied, the volunteers immersed their contralateral hand in a stirred water bath for which the temperature was set either to $46.5^{\circ} \mathrm{C}$ to induce CPM or to $33^{\circ} \mathrm{C}$ as innocuous control (29). After a resting period of $30 \mathrm{~min}$, the stimulation intensity corresponding to a pain level of NRS 50 was again determined (16). Another sequence of stimuli as described above followed, during which the water bath was set to whichever temperature had not been used previously. Volunteers were randomly assigned into couplets starting with either hot or innocuous water, and rated the painfulness of each temperature using the NRS. The water's temperature was electronically regulated and double-checked manually (Haake C10-K10, Thermo Fisher Scientific, USA; GTH 175/Pt, Greisinger Electronic, Germany).

\section{Data analysis and statistical analysis}

CPM was quantified for each individual at each session and for each conditioning stimulus as the relative change of the individual mean of the 20 values for the subjective pain ratings and the reflex responses during the conditioning stimulus compared with the individual mean of the 20 respective values before the conditioning stimulus. Outliers that deviated by $>2$ SDs from the means were removed.

To investigate the test-retest reliability of the effect of the conditioning stimuli on the subjective pain ratings and the reflex size, intraclass correlation coefficients (ICCs) were calculated (30). In contrast to simple correlation coefficients, ICCs take the intraindividual and interindividual variabilities into account to allow for an unbiased comparison of the test-retest reliability between the subjective pain ratings and the reflex size. ICC values $<0.4$ were considered to be poor, values between 0.4 and 0.75 were considered to be good and values $>0.75$ were considered to be excellent (31).

In addition to the ICC, standard correlations were performed to investigate whether the test-retest reliabilities of the measures are significantly influenced by the interindividual variability. ICCs account for such variability, while standard correlations do not.

All statistical analyses were performed using the $\mathrm{R}$ software package (R Foundation for Statistical Computing, Austria).

\section{General results}

\section{RESULTS}

Of the 40 volunteers included in the study, four were excluded from analysis: two volunteers did not return for the retest measurements; for one volunteer, the study had to be aborted due to intolerance of the hot water bath; and for one participant, the study had to be aborted due to technical problems with the electrophysiological equipment.

Questionnaire results, pain ratings of the conditioning stimuli, baseline responses to the test stimuli and the changes in subjective pain ratings and reflex size during the conditioning stimuli are shown in Table 1.

\section{Test-retest reliability of the effect of the CPM}

To compare the test-retest reliabilities of the changes in subjective pain ratings and reflex size during the conditioning stimuli, ICCs were calculated. Changes in subjective pain ratings showed ICCs of $0.54(95 \%$ CI 0.26 to 0.74$)$ for the hot water condition and 0.42 (95\% CI 0.12 to 0.66 ) for the control condition. Calculation of ICCs for the changes in reflex size resulted in 0.61 (95\% CI 0.36 to 0.78 ) for the hot water condition and 0.07 ( $95 \% \mathrm{CI}-0.26$ to 0.39 ) for the control condition.

The individual changes in subjective pain ratings and reflex size during the conditioning stimuli at test and retest and their correlations are shown in Figure 1.

\section{DISCUSSION}

The aim of the present study was to investigate and compare the testretest reliability of subjective pain ratings and the NFR to score the inhibitory effect by a conditioning stimulus on an electric test stimulus in healthy volunteers, a phenomenon termed CPM.

Our data show a good test-retest reliability for the subjective pain rating reductions during the hot water conditioning stimulus, consistent with previous findings (16-18). Similarly, we observed a good testretest reliability for NFR reductions during the hot water conditioning stimulus, comparable with that of the subjective pain ratings, although the NFR reduction was not significant for the whole group. However, the two scoring parameters differed regarding the effect of the control conditioning stimulus. 
TABLE 1

Questionnaire results, expectations, pain ratings of the conditioning stimuli, baseline responses to the test stimuli and changes in subjective pain ratings and reflex size during the conditioning stimulus

\begin{tabular}{|c|c|c|}
\hline & Test & Retest \\
\hline \multicolumn{3}{|c|}{ Questionnaire, median (range) } \\
\hline STAI-State & $35(22-68)$ & $34(21-68)$ \\
\hline STAI-Trait & $35(21-66)$ & $34(20-66)$ \\
\hline PSQ & $3.8(1.1-6.2)$ & $3.8(1.0-6.5)$ \\
\hline \multicolumn{3}{|c|}{$\begin{array}{l}\text { Expectations regarding the effects of stimuli on pain levels } \\
\text { (increased/no change/decreased) }\end{array}$} \\
\hline Hot water & $2 / 2 / 32$ & $3 / 10 / 23$ \\
\hline Control & $5 / 29 / 2$ & $1 / 31 / 4$ \\
\hline \multicolumn{3}{|c|}{ Pain ratings of the conditioning stimuli, median (range) } \\
\hline Hot water $\left(46.5^{\circ} \mathrm{C}\right)$ & $53(40-63)$ & $60(55-65)$ \\
\hline Control $\left(30^{\circ} \mathrm{C}\right)$ & $0(0-0)$ & $0(0-0)$ \\
\hline \multicolumn{3}{|c|}{ Baseline responses to the test stimuli, median (range) } \\
\hline Pain ratings & $52(48-55)$ & $52(49-55)$ \\
\hline Reflex response & $7.3(4.8-8.1)$ & $7.5(5.6-8.6)$ \\
\hline \multicolumn{3}{|c|}{ Changes during conditioning stimulus, $\%$, median $(95 \% \mathrm{Cl})$} \\
\hline \multicolumn{3}{|l|}{ Hot water $\left(46.5^{\circ} \mathrm{C}\right)$} \\
\hline Pain ratings & $-8.5(-15$ to -2.0$)$ & $-8.8(-16.6$ to -1.0$)$ \\
\hline Reflex responses & $-12.1(-28.1$ to 3.9$)$ & $-11.5(-30.7$ to 7.8$)$ \\
\hline \multicolumn{3}{|l|}{ Control $\left(33^{\circ} \mathrm{C}\right)$} \\
\hline Pain ratings & $1.7(-2.5$ to 6.0$)$ & $-0.9(-5.5$ to 3.6$)$ \\
\hline Reflex responses & $-3.7(-19.3$ to 11.9$)$ & $-5.6(-18.9$ to 7.7$)$ \\
\hline
\end{tabular}

PSQ Pain Sensitivity Questionnaire; STAI Spielberger's State/Trait Anxiety Inventory

During the control conditioning stimulus, our data revealed a good correlation between the individual changes in subjective pain ratings at the test session compared with the retest session. For the NFR, in contrast, we found no test-retest correlation for the individual effects during the control conditioning stimulus.

The most parsimonious explanation for this difference would be to assume an influence of confounders that affect the individual change in subjective pain ratings during the control conditioning stimulus while having no effect on the NFR, which is well established for several cognitive influences (3,32-34).

It has been shown that CPM involves mechanisms on several levels, including modulation on the cerebral level via cortico-cortical interactions as well as modulation on the cerebro-spinal level via descending pathways $(7,10,35,36)$. Especially for the cognitive modulation of CPM through changes in attention, expectation and emotion, it has been shown that modulation at the cerebral level plays an important role (32,37-39). Because the NFR can only reflect the effect of the descending pathways while the subjective pain ratings incorporate all mechanisms, cognitive modulation can be expected to influence NFR and subjective pain ratings to a different extent.

Such cognitive influences may, therefore, account for the testretest correlation of subjective pain rating changes during the control conditions, by creating a confounder that remains at a stable degree and direction between the test and the retest session in each individual, while varying to a larger extent among individuals.

However, if such confounders influence the subjective pain ratings during the innocuous control stimulus measurements, they are likely to have an influence during the hot water conditioning stimulus as well. Therefore, the good test-retest reliability observed for the changes in subjective pain ratings during the hot water conditioning stimulus could, in part, be ascribed to these cognitive influences. The NFR, in contrast, for which no test-retest correlation of its changes during the control conditioning stimulus was observed, appears to be less affected by cognitive influences. The comparable reliabilities for the subjective pain ratings and the NFR may, therefore, be based on at

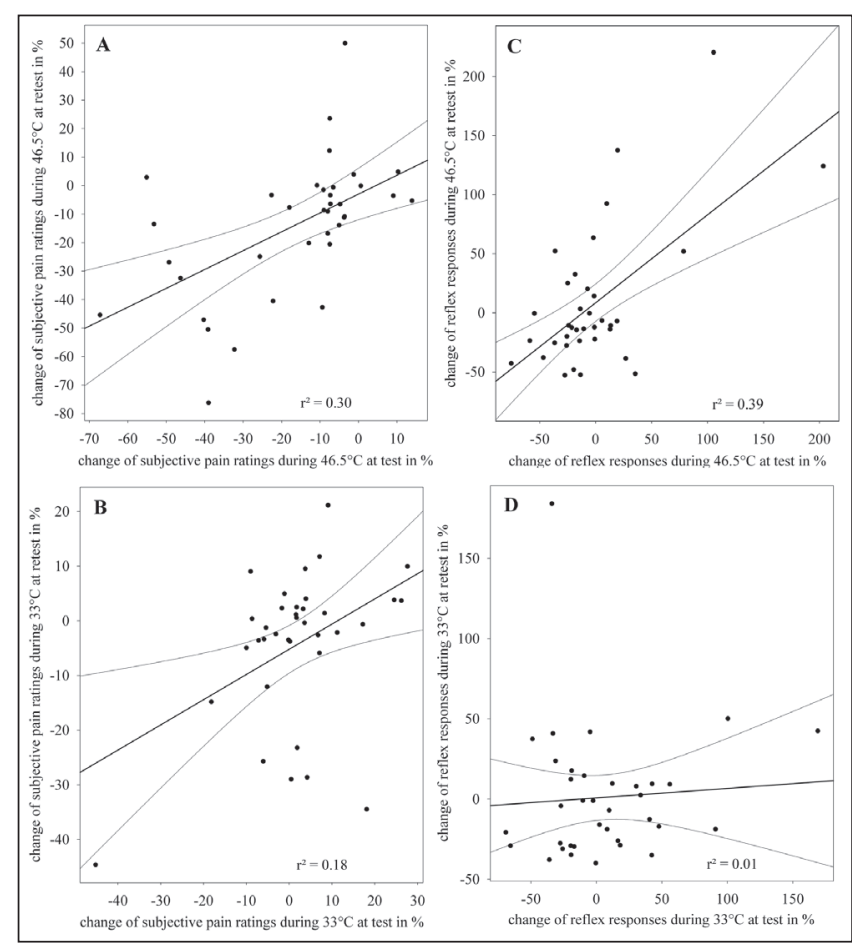

Figure 1) Correlations between the individual changes in subjective pain ratings and reflex size during the hot water $\left(46.5^{\circ} \mathrm{C}\right)$ and control $\left(33^{\circ} \mathrm{C}\right)$ conditioning stimuli at the test session compared with the retest session. Subjective pain ratings are shown for the hot water condition (A) and for the control condition (B). Reflex responses are shown for the hot water condition (C) and for the control condition (D)

least partially different mechanisms. While the subjective pain ratings incorporate the associated cognitive mechanisms to a larger extent, the NFR instead reflects the nociceptive processes at spinal level.

In our study design, we used pain rating tailored test stimuli for better comparability with previous studies because all previous studies on the reliability of CPM investigated pain ratings only. However, our design increases the population variability of the reflex responses in comparison to the subjective pain ratings. Because the different population variabilities could influence the test-retest reliability as measured by the ICCs, we additionally performed a correlation analysis, showing that the overall results stay the same, whether the intraindividual variability is (ICCs), or is not (standard correlation) taken into account.

The different interindividual variabilities due to the study design may also explain why we found a significant reduction of subjective pain ratings during the conditioning hot water stimulus, while NFR reductions did not reach statistical significance. Because the aim of our study was to investigate the reliability of the individual inhibition, the significance of the inhibition of the whole group is only of interest to confirm that the overall setup is valid to induce inhibition. That the NFR, similar to the subjective pain ratings, is reduced during a hot water conditioning stimulus has been shown in numerous studies. Therefore, the sample size calculation was optimized for the parameter with the lower variability (subjective pain ratings), which already confirms the validity of the setup.

However, because our data show no significant inhibition of the NFR, it is difficult to draw conclusions regarding the reliability of the NFR. Possibly this was only due to the sample size, but it is also possible that our setup was not effective in inducing a CPM effect on the NFR, in which case the reliabilities reported here could not be regarded as reliabilities of the CPM effect.

For the conditioning stimulus, we chose tonic heat pain set to $46.5^{\circ} \mathrm{C}$, as previously suggested (29). The tonic heat stimulus appears to be more constant and less confounded by changes in cardiovascular activity compared with the cold water stimulus (40). 


\section{SUMMARY}

We have shown a good test-retest reliability for both the subjective pain ratings and the NFR reduction to quantify the effect of a painful hot water conditioning stimulus on a painful electric test stimulus. Conclusions regarding the NFR reliability remain difficult because the reflex reduction did not reach significance on the group level, most likely due to its larger variability in our study design. However, the good reliability of the subjective pain ratings may, at least in part, be ascribed to cognitive influences. These influences appear to account for the testretest correlation of subjective pain rating changes during the control conditions, by creating a confounder that remains at a stable degree and direction between the test and the retest session in each individual while varying among the individuals in a larger extent. Reflex responses appear to be less influenced by these cognitive influences, leading to the assumption that the NFR provides a tool that more purely reflects the CPM effect in terms of nociceptive mechanism. Therefore, if cognitive influences are considered to be a relevant part of a specific research question, subjective pain ratings appear to be the method of choice to score the effect of CPM. However, if the primary research question is the effect of CPM on nociception, with less interest in the cognitive influences, the NFR appears to be the method of choice to score the CPM.

FUNDING AND DISCLOSURES: This study was funded through the Internal Research Funding of the Department of Anesthesiology and Intensive Care Medicine, Charité - Universitätsmedizin Berlin. Dr von Dincklage is a participant in the Friedrich C Luft Clinical Scientist Pilot Program funded by Volkswagen Foundation and Charité Foundation. The authors have no conflicts of interest or financial interests regarding the study.

\section{REFERENCES}

1. Pud D, Granovsky Y, Yarnitsky D. The methodology of experimentally induced diffuse noxious inhibitory control (DNIC)-like effect in humans. Pain 2009;144:16-9.

2. Lewis GN, Rice DA, McNair PJ. Conditioned pain modulation in populations with chronic pain: A systematic review and metaanalysis. J Pain 2012;13:936-44.

3. Van Wijk G, Veldhuijzen DS. Perspective on diffuse noxious inhibitory controls as a model of endogenous pain modulation in clinical pain syndromes. J Pain 2010;11:408-19.

4. Yarnitsky D, Crispel Y, Eisenberg E, et al. Prediction of chronic post-operative pain: Pre-operative DNIC testing identifies patients at risk. Pain 2008;138:22-8.

5. Wilder-Smith OH, Schreyer T, Scheffer GJ, Arendt-Nielsen L. Patients with chronic pain after abdominal surgery show less preoperative endogenous pain inhibition and more postoperative hyperalgesia: A pilot study. J Pain Palliat Care Pharmacother 2010;24:119-28.

6. Yarnitsky D, Arendt-Nielsen L, Bouhassira D, et al. Recommendations on terminology and practice of psychophysical DNIC testing. Eur J Pain 2010;14:339.

7. Sprenger C, Bingel U, Büchel C. Treating pain with pain: Supraspinal mechanisms of endogenous analgesia elicited by heterotopic noxious conditioning stimulation. Pain 2011;152:428-39.

8. Le Bars D. The whole body receptive field of dorsal horn multireceptive neurones. Brain Research Reviews 2002;40:29-44.

9. Villanueva L, Le Bars D. The activation of bulbo-spinal controls by peripheral nociceptive inputs: Diffuse noxious inhibitory controls. Biol Res 1995;28:113-25.

10. Piché M, Arsenault M, Rainville P. Cerebral and cerebrospinal processes underlying counterirritation analgesia. J Neurosci 2009;29:14236-46.

11. Sandrini G, Serrao M, Rossi P, Romaniello A, Cruccu G, Willer JC. The lower limb flexion reflex in humans. Prog Neurobiol 2005;77:353-95.

12. Bartley EJ, Rhudy JL. Endogenous inhibition of the nociceptive flexion reflex (NFR) and pain ratings during the menstrual cycle in healthy women. Ann Behav Med 2012;43:343-51.

13. Von Dincklage F, Hackbarth M, Schneider M, Baars JH, Rehberg B. Introduction of a continual RIII reflex threshold tracking algorithm. Brain Res 2009;1260:24-9.

14. Skljarevski V, Ramadan $\mathrm{N}$. The nociceptive flexion reflex in humans - review article. Pain 2002;96:3-8.
15. Lewis GN, Rice DA, Jourdain K, McNair PJ. Influence of stimulation location and posture on the reliability and comfort of the nociceptive flexion reflex. Pain Res Manag 2012;17:110-4.

16. Lewis GN, Heales L, Rice DA, Rome K, McNair PJ. Reliability of the conditioned pain modulation paradigm to assess endogenous inhibitory pain pathways. Pain Res Manag 2012;17:98-102.

17. Cathcart S, Winefield AH, Rolan P, Lushington K. Reliability of temporal summation and diffuse noxious inhibitory control. Pain Res Manag 2009;14:433-8.

18. Arendt-Nielsen L, Andresen T, Malver LP, Oksche A, Mansikka H, Drewes AM. A double-blind, placebo-controlled study on the effect of buprenorphine and fentanyl on descending pain modulation: A human experimental study. Clin J Pain 2012;28:623-7.

19. Rhudy JL, Bartley EJ. The effect of the menstrual cycle on affective modulation of pain and nociception in healthy women. Pain 2010;149:365-72.

20. Tassorelli C, Sandrini G, Cecchini AP, Nappi RE, Sances G, Martignoni E. Changes in nociceptive flexion reflex threshold across the menstrual cycle in healthy women. Psychosom Med 2002;64:621-6.

21. Sandrini G, Alfonsi E, Bono G, Facchinetti F, Montalbetti L, Nappi G. Circadian variations of human flexion reflex. Pain 1986;25:403-10.

22. French DJ, France CR, France JL, Arnott LF. The influence of acute anxiety on assessment of nociceptive flexion reflex thresholds in healthy young adults. Pain 2005;114:358-63.

23. Ruscheweyh R, Marziniak M, Stumpenhorst F, Reinholz J, Knecht S. Pain sensitivity can be assessed by self-rating: Development and validation of the Pain Sensitivity Questionnaire. Pain 2009;146:65-74.

24. Sandrini G, Arrigo A, Bono G, Nappi G. The nociceptive flexion reflex as a tool for exploring pain control systems in headache and other pain syndromes. Cephalalgia 1993;13:21-7.

25. Rehberg B, Baars JH, Kotsch J, Koppe P, von Dincklage F. Comparison of trigeminal and spinal modulation of pain and nociception. Int J Neurosci 2012;122:298-304.

26. Rhudy JL, Green BA, Arnau RC, France CR. Taxometric analysis of biceps femoris EMG following electrocutaneous stimulation over the sural nerve: Determining the latent structure of the nociceptive flexion reflex (NFR). Int J Psychophysiol 2008;69:18-26.

27. Levitt H. Transformed up-down methods in psychoacoustics. J Acoust Soc Am 1971;49(Suppl 2):467+.

28. Dimitrijević MR, Faganel J, Gregorić M, Nathan PW, Trontelj JK. Habituation: Effects of regular and stochastic stimulation. J Neurol Neurosurg Psychiatry 1972;35:234-42.

29. Granot M, Weissman-Fogel I, Crispel Y, et al. Determinants of endogenous analgesia magnitude in a diffuse noxious inhibitory control (DNIC) paradigm: Do conditioning stimulus painfulness, gender and personality variables matter? Pain 2008;136:142-9.

30. Shrout PE, Fleiss JL. Intraclass correlations: Uses in assessing rater reliability. Psychol Bull 1979;86:420-8.

31. Shoukri MM. Statistical Methods for Health Sciences, 2nd edn. Boca Raton: CRC Press, 1999.

32. Ladouceur A, Tessier J, Provencher B, Rainville P, Piché M. Top-down attentional modulation of analgesia induced by heterotopic noxious counterstimulation. Pain 2012;153:1755-62.

33. Terry EL, Kerr KL, DelVentura JL, Rhudy JL. Anxiety sensitivity does not enhance pain signaling at the spinal level. Clin J Pain 2012;28:505-10.

34. Rhudy JL, Martin SL, Terry EL, et al. Pain catastrophizing is related to temporal summation of pain but not temporal summation of the nociceptive flexion reflex. Pain 2011;152:794-801.

35. Broucker TD, Cesaro P, Willer JC, Bars DL. Diffuse noxious inhibitory controls in man: Involvement of the spinoreticular tract. Brain 1990;113:1223-34.

36. Moont R, Crispel Y, Lev R, Pud D, Yarnitsky D. Temporal changes in cortical activation during conditioned pain modulation (CPM), a LORETA study. Pain 2011;152:1469-77.

37. Moont R, Crispel Y, Lev R, Pud D, Yarnitsky D. Temporal changes in cortical activation during distraction from pain: A comparative LORETA study with conditioned pain modulation. Brain Res 2012;1435:105-17.

38. Goffaux P, Redmond WJ, Rainville P, Marchand S. Descending analgesia - when the spine echoes what the brain expects. Pain 2007;130:137-43.

39. Roy M, Lebuis A, Peretz I, Rainville P. The modulation of pain by attention and emotion: A dissociation of perceptual and spinal nociceptive processes. Eur J Pain 2011;15:641.e1-10.

40. Streff A, Kuehl LK, Michaux G, Anton F. Differential physiological effects during tonic painful hand immersion tests using hot and ice water. Eur J Pain 2010;14:266-72. 


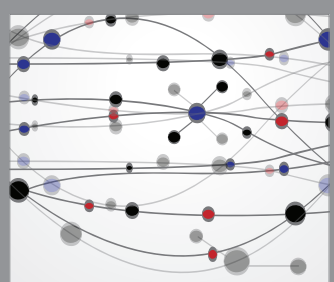

The Scientific World Journal
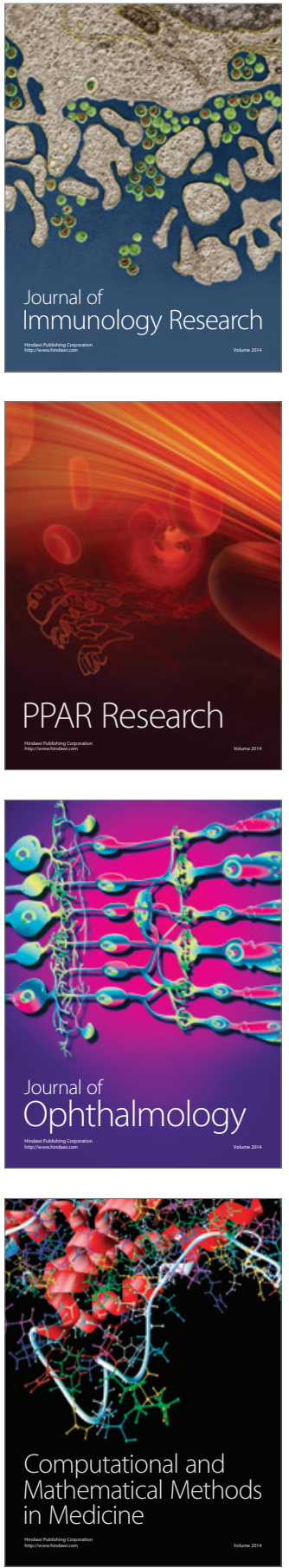

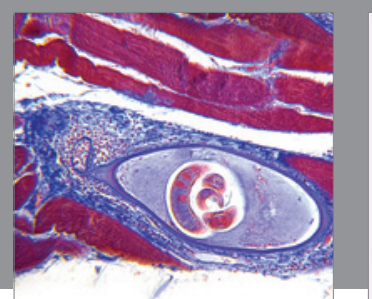

Gastroenterology Research and Practice

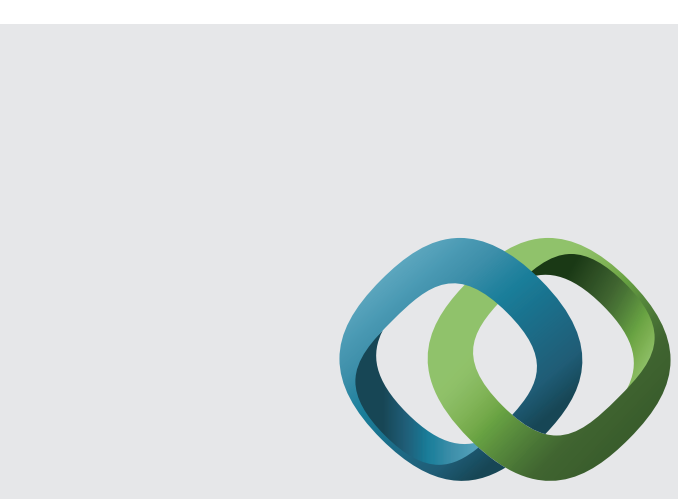

\section{Hindawi}

Submit your manuscripts at

http://www.hindawi.com
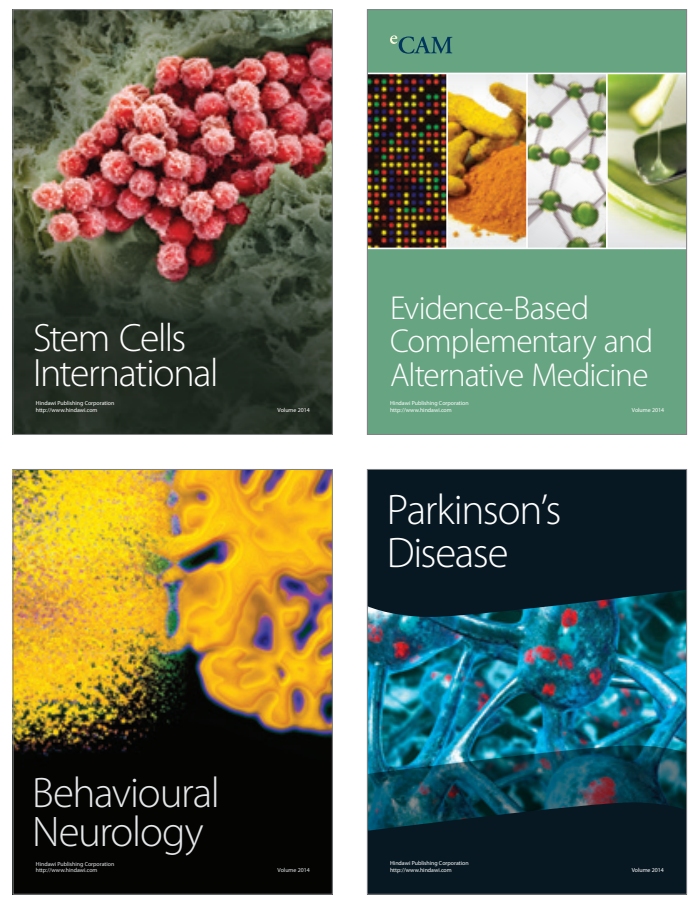
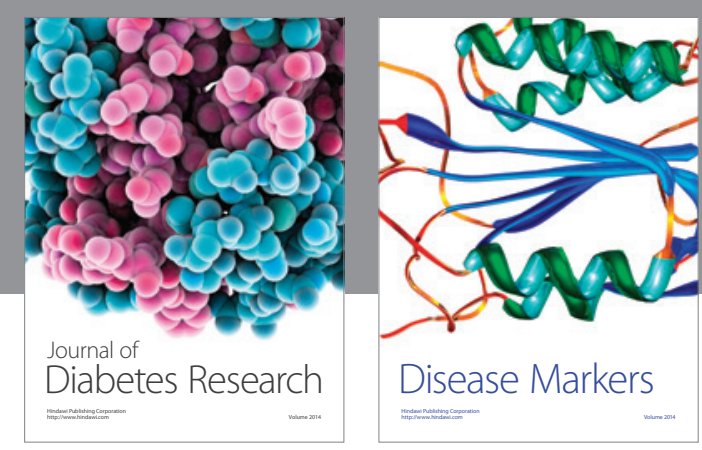

Disease Markers
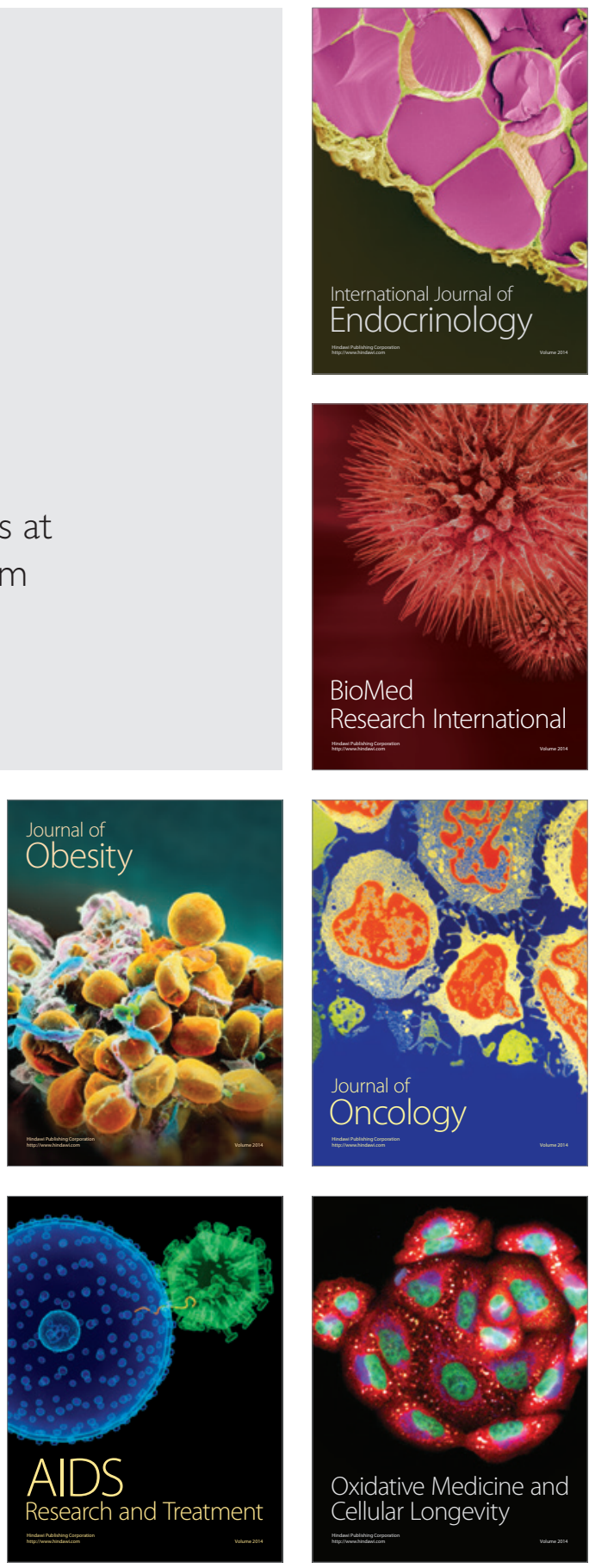